\title{
EDUCAÇÃO E TRABALHO: A FORMAÇÃO DO SUJEITO E A SOCIEDADE DE MERCADO
}

\author{
Rogério Rodrigues
}

\begin{abstract}
RESUMO
Pensar as relações entre educação e trabalho requer analisar como o sujeito se encontra inserido na sociedade contemporânea regida pelas relações de mercado. A intencionalidade do governo e de educadores na implementação das propostas de ensino pautadas na constituição da democracia e no exercício da cidadania requer um tipo de sujeito crítico, e isso entra em contradição com as determinações do mercado. O objetivo desse artigo é apresentar ao leitor uma reflexão sobre os limites e as possibilidades de implementar propostas educativas nas interfaces entre os campos da educação e do trabalho. Para tanto, tem-se como proposição teórica analisar e interpretar a área temática entre educação e trabalho e, principalmente, saber como se realiza essa junção na unidade de ensino. Diria que essas diversas junções de práticas educativas que ocorrem na unidade de ensino são produções incontroláveis que resultam das tramas de relações humanas que instituem e produzem o sujeito.
\end{abstract}

Palavras-Chave: Educação. Filosofia da Educação. Educação e Trabalho. Educação e Sociedade.

\begin{abstract}
Thinking about the relationship between education and work requires to analyze how the subject is inserted in contemporary society governed by market relations. The intention of the government and educators in implementing the education proposals guided by the constitution of democracy and citizenship requires a kind of critical subject, and it contradicts the determinations of the market. The aim of this paper is to present the reader a reflection about the limits and possibilities of implementing educational projects in the interfaces, between the fields of education and work. For this, it's necessary to analyze and interpret the theoretical thematic area between education and work, and especially to know how to realize this proposal in teaching units. I would say these various junctions of educational practices, that happen in the teaching unit, are uncontrollable productions resulting from plots of establishing human relationships that produce the subject.
\end{abstract}

Keywords: Education. Philosophy of Education. Education and Work. Education and Society. 


\section{A EDUCAÇÃO dO SUJEITO ENTRE O MUNDO DO TRABALHO E O TEMPO LIVRE}

Em grande parte, o senso comum como uma narrativa sobre real destituído do argumento lógico e contraditória, reconhece que vivemos numa sociedade pautada exclusivamente na obtenção do lucro através da produção e no consumo de coisas, portanto, ora estamos inseridos no mundo trabalho, ora estamos usufruindo o tempo livre consumindo diversas coisas. Nesse vai e vem entre a produção e o consumo, pode-se abrir uma questão, qual seja: o que é o sujeito perante o mundo do trabalho, principalmente, inserido na sociedade de mercado que determina suas necessidades de consumo?

O sujeito alinhado ao capitalismo seria a possibilidade de empregá-lo na cadeia produtiva e ampliar ao máximo sua capacidade de produção e consumo para obter, respectivamente, mais valor como resultado da produção de mercadorias ou consumidor de coisas que movimenta toda a cadeia produtiva.

Do lado do próprio sujeito fica uma incógnita sobre a possibilidade de empregar-se com o objetivo de garantir sua subsistência e garantir sua capacidade de consumo ao vender a força de trabalho.

Neste aspecto, responder o que é o sujeito perante a sociedade do mercado se reduz numa simples resposta de prepará-lo para inserir no mundo do trabalho e caracterizá-lo como consumidor.

Diríamos que a educação possui um papel primordial nesse objetivo específico de tornar o sujeito moderno como aquele que é produtor e consumidor, e isso se reduz em instrumentalizá-lo para o desempenho de funções próprias do trabalho e do consumo.

O modo de vida capitalista se insere desde cedo no cotidiano das pessoas ao ponto de não sabermos mais ser diferente nessa simples equação que nos posiciona entre a produção e consumo. Neste caso, grande parte das políticas públicas educacionais se pautam no argumento do senso comum em apenas incorporar como objetivo educacional o de apenas favorecer a educação como um elemento associado ao preparo para o trabalho, como, por exemplo, o Programa Nacional de Acesso ao Ensino Técnico e Emprego (Pronatec), que foi criado pelo Governo Federal em 2011 e que tem como "[...] objetivo ampliar a oferta de cursos de educação profissional e tecnológica" (BRASIL, 2013). 
A educação para o consumo já é trabalhada desde cedo, pois, já na infância, todos os territórios são ocupados por objetos de consumo. Estes possuem suas marcas de fabricantes que delimitam os gostos dos sujeitos, pois eles encontram-se atrelados por um conjunto de situações que o delimitam a sentir necessidades de coisas.

Compreendemos que é preciso romper com o senso comum do consumo aleatório e sem responsabilidade, pois é necessário pensar as relações entre a educação do sujeito com o mundo do trabalho e o consumo para além dos determinantes do mercado que está pautado na lógica da obtenção do lucro. O ideal seria uma educação que permita ao sujeito tornar-se verdadeiramente crítico e consciente do seu tempo e que possa estabelecer uma harmonia com todas as formas de vida do planeta. Essa postura é algo a mais que uma simples ecologia, portanto:

Não seria exagero enfatizar que a tomada de consciência ecológica futura não deverá se contentar com a preocupação com fatores ambientais, mas deverá também ter como objeto devastações ecológicas no campo social e no domínio mental. Sem transformação das mentalidades e dos hábitos coletivos haverá apenas medidas ilusórias relativas ao meio material. (GUATTARI, 2000, p. 173).

O ponto de partida para essa ruptura seria o reconhecimento de que somos sujeitos que nos inserimos num mundo já estabelecido e que já possuímos um conjunto de dinâmicas que determinam a produção e o consumo. Como já foi pronunciado que:

[...] na produção social da sua existência, os homens estabelecem relações determinadas, necessárias, independentes da sua vontade, relações de produção que correspondem a um determinado grau de desenvolvimento das forças produtivas materiais. $\mathrm{O}$ conjunto destas relações de produção constitui a estrutura econômica da sociedade, a base concreta sobre a qual se eleva uma superestrutura jurídica e política e à qual correspondem determinadas formas de consciência social. O modo de produção da vida material condiciona o desenvolvimento da vida social, política e intelectual em geral. Não é a consciência dos homens que determina o seu ser; é o seu ser social que, inversamente, determina a sua consciência. (MARX, 1983, p. 24).

As perguntas, em termos educacionais, deveriam ser: como seria possível a educação do sujeito radicalizar sua compreensão e romper com esses determinantes históricos que o condicionam no campo da produção e no consumo? Seria possível indicar práticas sociais que possam de fato realizar os elementos de sustentabilidade e, precisamente, uma ecologia pautada num equilíbrio entre a produção e consumo que atenda aos interesses da grande parcela da população e do meio ambiente restaurando relações sociais harmônicas? Isso demanda um tipo de subjetividade que 
esteja implicada com a preservação com a vida. Essa possível ruptura é indica por Adorno (1995) na pressuposição de que:

Como hoje em dia é extremamente limitada a possibilidade de mudar os pressupostos objetivos, isto é, sociais e políticos que geram tais acontecimentos, as tentativas de se contrapor à repetição de Auschwitz são impelidas necessariamente para o lado subjetivo. [...] A educação tem sentido unicamente como educação dirigida a uma auto-reflexão crítica. (ADORNO, 1995, p. 121).

Neste caso, a educação, mais propriamente a educação relacionada ao mundo do trabalho e do consumo, passa a ser um elemento central para se compreender a categoria de sujeito no âmbito da sociedade de mercado.

O trabalho é algo que pode qualificar ou desqualificar o sujeito e primordialmente, definir sua existência em sociedade. O Capitalismo determina a condição que qualifica o sujeito que está diretamente relacionado com o acúmulo de conhecimentos próprios para constituir-se em força de trabalho e, principalmente, pelo lugar que o sujeito ocupa na hierarquia da cadeia produtiva.

Para muitos, o Capitalismo não se apresenta ao sujeito com alguma questão crucial, pois o sujeito é algo determinado para somente atender a demanda em realizar a produção e o consumo de coisas. Neste caso, trata-se apenas de adequá-lo às funções próprias da divisão social do trabalho e, portanto, necessita de uma escola que venha reforçar as representações simbólicas que justificam a hierarquia social (BOURDIEU; PASSERON, 1982). Nesta concepção de sujeito, a educação é um processo de integrá-lo ao modo normal de existência que se constitui como sendo o ausente de qualquer tipo de conflito.

Essa concepção de sujeito na sociedade de mercado se representa como aquele que, o mais breve possível, possa se inserir ao modo de produção capitalista. No entanto, como podemos pensar a questão do sujeito no campo da teoria crítica tendo como base as possíveis relações de produção e consumo que se estabelecem entre educação e trabalho?

Podemos compreender que temos dificuldade em reconhecer a falta de junção entre as diversas esferas que circunscrevem o sujeito no campo do social. Portanto, educar o sujeito para se inserir e adequar-se ao sistema produtivo acaba por se pautar no paradoxo da exclusão e, principalmente, num sistema de produção que o adoece por completo no campo das relações humanas, sobre o qual Freud (1996) já tinha anunciado que: 
O elemento de verdade por trás disso tudo, elemento que as pessoas estão tão dispostas a repudiar, é que os homens não são criaturas gentis que desejam ser amadas e que, no máximo, podem defender-se quando atacadas; pelo contrário, são criaturas entre cujos dotes instintivos deve-se levar em conta uma poderosa quota de agressividade. Em resultado disso, o seu próximo é, para eles, não apenas um ajudante potencial ou objeto sexual, mas também alguém que os tenta satisfazer sobre ele a sua agressividade, a explorar sua capacidade de trabalho sem compensação, utilizá-lo sexualmente sem o seu consentimento, apoderar-se de suas posses, humilhá-lo, causar-lhe sofrimento, torturá-lo e matá-lo - Homo homini lupus. (FREUD, 1996, p. 116).

Diríamos que para que se possa transparecer a bondade no sujeito deve ocorrer um determinado trabalho (educativo) de contenção da agressividade para que este se torne corretamente produtivo e consumidor. No entanto, a saída freudiana é mais proveniente, afirmando a impossibilidade de o sujeito redirecionar toda sua agressividade, mas resta saber

\begin{abstract}
Quais os meios que a civilização utiliza para inibir a agressividade que se lhe opõe, torná-la inócua ou, talvez, livrar-se dela? [...] O que acontece neste para tornar inofensivo seu desejo de agressão? Algo notável, que jamais teríamos adivinhado e que, não obstante, é bastante óbvio. Sua agressividade é introjetada, internalizada; ela é, na realidade, enviada de volta para o lugar de onde proveio, isto é, dirigida no sentido de seu próprio ego. Aí, é assumida por uma parte do ego, que coloca contra o resto do ego, como superego, e que então, sob a forma de 'consciência', está pronta para pôr em ação contra o ego a mesma agressividade rude que o ego teria gostado de satisfazer sobre outros indivíduos, a ele estranhos. A tensão entre o severo superego e o ego, que a ele se acha sujeito, é por nós chamada de sentimento de culpa; expressa-se como uma necessidade de punição. A civilização, portanto, consegue dominar o perigoso desejo de agressão do indivíduo, enfraquecendo-o, desarmandoo e estabelecendo no seu interior um agente para cuidar dele, como uma guarnição numa cidade conquistada. (FREUD, 1996, p. 127).
\end{abstract}

Essa modalidade de controle do sujeito seria aquela que também faz com que este perca por completo sua sensibilidade e compaixão e o torna como uma peça de máquina. Este sujeito também acaba por exigir que todos sejam apêndice da máquina. Esse seu sintoma é o que o inclui nas especificidades do sistema produtivo e o torna dócil e amplamente habilitado num sistema pautado em vigiar e punir (FOUCAULT, 1991).

Cabe aqui analisar que a determinação do sujeito em querer fazer algo no mundo do trabalho pode estar associada a condições obsessivas que o impedem de avaliar no campo da teoria crítica o conjunto das relações do trabalho que possam evidenciar as contradições presentes nas práticas sociais desempenhadas no cotidiano. Essa seria uma das grandes questões para se compreender o como e o porquê da dedicação dos trabalhadores que executaram com muita eficiência todo um 
conjunto de situações que produziram inclusive a bárbarie. Neste caso, o que se pode afirmar em relação à dedicação dos engenheiros alemães é que eles fizeram e aplicaram toda uma técnica própria para promover exterminação indiferente ao sofrimento alheio, portanto:

\begin{abstract}
Não se sabe com certeza como se verifica a fetichização da técnica na psicologia individual dos indivíduos, onde está o ponto de transição entre uma relação racional com ela e aquela supervalorização, que leva, em última análise, quem projeta um sistema ferroviário para conduzir as vítimas a Auschwitz com maior rapidez e fluência, a esquecer o que acontece com estas vítimas em Auschwitz. (ADORNO, 1995, p. 133).
\end{abstract}

Esses elementos educativos que se estabelecem no limite entre o uso da técnica coisificada e a teoria crítica seria o pressuposto de que é preciso reconhecer que a presença do sujeito na sociedade de mercado é algo que por si só já pode evidenciar uma crise na educação e no trabalho.

Essa crise da educação pode se evidenciar no sujeito nas diversas dificuldades que se apresentam quando se busca aplicar os elementos constituintes da cidadania e justiça, principalmente, a conquista dos direitos estabelecidos pelo Estado. Temos um conjunto de barreiras objetivas e subjetivas que impedem a transmissão da cultura na unidade escolar e, portanto, a impossibilidade de concretizar objetivos educacionais que possam favorecer seu desenvolvimento social e político - a cidadania.

No tocante à questão da cidadania versus transmissão escolar, isso aponta diretamente para uma crise na educação em que seria preciso analisá-la como algo que também se apresenta nas avaliações governamentais sobre o desempenho das escolas, pois elas não indicam algo promissor e, portanto, vem reforçar que algo de fato impede a transmissão dos conteúdos clássicos da ciência.

Segundo os dados oficiais, em 2011 a taxa de abandono no sistema escolar brasileiro no ensino fundamental era de $2,8 \%$, o que corresponde para o número de matriculado de 30.358 .640 ao número de abandono de 850.042 alunos. Já no ensino médio, a taxa de abandono era de 9,5\%, o que corresponde para o número de matriculados de 8.400.689 ao número de abandono de 798.066 alunos. (INEP, 2013). No entanto, é importante destacar que há uma redução de alunos matriculados do ensino fundamental para o ensino médio de 21.957.951 alunos. (INEP, 2013).

Esses dados são alarmantes e, por algum motivo e sem justificativa alguma, em 2012, o Governo deixa de divulgar os dados referentes aos indicadores de rendimento escolar, que apresentavam as taxas de aprovação, de reprovação e, 
principalmente, de abandono, segundo a região geográfica e a unidade da federação, mantendo apenas os indicadores de concluintes do ensino, por localização e dependência administrativa, segundo a região geográfica e a unidade da federação.

No entanto, ainda prevalece a diferença de alunos matriculados no ensino fundamental para o ensino médio, ou seja, há matriculado atualmente no ensino fundamental 29.702.498 alunos e no ensino médio, 8.376.852. Isso ainda representa uma grande diferença na ordem de 21.325.646 alunos que deixam de estudar (INEP, 2013).

Esses indicadores oficiais apontam para existência da falta de compreensão do que seriam os elementos básicos de implementação de política pública para o setor educacional que possa de fato garantir o direito constitucional do acesso à educação básica. Levando-se em consideração que aqueles que se mantêm no sistema escolar também apresentam "problemas de aprendizagem”, isso faz surgir outra questão crucial, qual seja: em termos fundamentais, no campo da transmissão do saber, apresenta-se uma crise na educação que também deve atingir diretamente a esfera do mundo do trabalho. Essa falência na educação também fica em evidência no crescimento do índice de analfabetismo do País, que passou de $8,4 \%$ para $8,5 \%$ entre 2011 e 2012, segundo a pesquisa anual do IBGE (2012).

Esses indicadores apontam para o fato de que o aparelho escolar tem dificuldade de realizar-se como um aparelho de acesso à cultura para toda a população. Portanto, ocorre um paradoxo ao se pensar a cidadania como uma questão diretamente relacionada com a aprendizagem escolar na premissa de alterar o comportamento do sujeito para a vida.

Em grande parte, os projetos pedagógicos e os planos de ensino escolares estabelecem como objetivo educacional "formar o cidadão" e "promover a cidadania". Contudo as práticas educativas encontram dificuldades para aplicar esses princípios educacionais. Pouco se compreende o que seria a cidadania de fato e, paradoxalmente, ocorre uma ênfase em quantificar, por diversos instrumentos, os procedimentos educativos no aparelho escolar que vêm reforçar as falências na educação.

Esses procedimentos avaliativos perdem o sentido no tocante a dimensionar a qualidade do ensino. A quantidade de sujeitos que ingressam no sistema escolar e seu fluxo não correspondem diretamente com a qualidade do aparelho escolar em transmitir os conteúdos clássicos da ciência. 
A partir dessa pequena problematização presente no eixo da inserção do sujeito no projeto educacional e no mundo do trabalho é que encontramos um enfrentamento em termos de pesquisa no sentido de estabelecer no referido tema uma determinada concepção de prática educativa que possa restabelecer uma posição crítica sobre a ideia de sujeito perante a sociedade de mercado.

\section{EDUCAÇÃO E TRABALHO: A PRODUÇÃO DO SUJEITO NO CAMPO DAS RELAÇÕES EDUCATIVAS E NO TRABALHO}

$\mathrm{Na}$ contemporaneidade, há uma tendência permanente para o desemprego do sujeito da cadeia produtiva, pois as políticas públicas cometem o engano de somente focar o planejamento educional em quantificar o fluxo no processo de escolarização, sem analisar as necessidades previsíveis de ocupação dos postos de trabalhos que permitam a inserção do sujeito no mundo do trabalho.

Há ainda outro agravante que também amplia o referido problema, qual seja: a tendência da desocupação do sujeito da cadeia produtiva ocorre, principalmente, em decorrência de os processos produtivos estarem sendo plenamente automatizados por robôs que fazem a tarefa de vários trabalhadores da linha de produção.

Em oposição a essa situação, aqueles que se encontram empregados realizam um tipo de trabalho que, na maioria das vezes, não proporciona a qualidade do pensamento humano, pois parte trata apenas da repetição exaustiva da mesma tarefa, de se fazer gestos programados que, no campo da ergonomia, o limitam em possibilidades de expressar-se corporalmente.

Tendo isso como uma ocorrência, é possível estabelecer a pressuposição de que o processo de escolarização e o mundo do trabalho são lugares de desencontros e de diversas dificuldades, em que o sujeito não se realiza na plenitude. Portanto, a educação e a empregabilidade do sujeito é um fato casual que é determinado somente pela lógica do mercado.

Em grande parte da minha atuação como educador, tive que conviver com a dificuldade em compreender esse paradoxo do sujeito ao inserir-se na sociedade de mercado. O paradoxo se refere em educar o sujeito para um sistema que o mantém na desigualdade entre a produção coletiva e a concentração da riqueza produzida. Esse modelo de organização social também modela os modos de ser sujeito, pois no âmbito da tradição marxista o sujeito é o fruto das relações sociais (MARX, 1983). 
No entanto, o que seria o sujeito na radicalidade viver numa sociedade em que este se encontra subordinado ao capital no campo das relações de produção?

Parte-se do pressuposto de que o sujeito na sociedade de mercado é coisificado, pois o modo de produção capitalista tende a transformar tudo em mercadoria. Essa tendência acaba por coisificar também as relações humanas e, até mesmo, o próprio homem. Isso está na base das relações capitalistas, em que se estabelece "[...] a condição para que o dinheiro se transforme em capital é que o proprietário de dinheiro possa trocar dinheiro pela capacidade de trabalho de outrem, enquanto mercadoria" (MARX, 1983, p. 323).

Diríamos que essa concepção em compreender o sujeito como objeto de uso/mercadoria no modelo de produção capitalista é intensa e determina em grande parte o pensamento educacional no sentido de tornar o sujeito produtivo como uma peça de engrenagem de máquina.

Em contraposição a essa situação avaliamos que seria importante desenvolver uma linha de pesquisa que tenha como campo de investigação a educação e o trabalho que deveria favorecer indicativos de rupturas para a compreensão do sujeito emancipado, como a montagem de um grande quebra-cabeça, em que sempre falta algo para totalizar o pensamento crítico.

Esse tema sobre a emancipação do sujeito em contraposição às amarras da sociedade do mercado estabelece o problema de como seria possível produzir práticas educativas críticas numa sociedade que se encontra pautada no paradigma da exploração do sujeito nas interfaces das esferas entre a educação e o trabalho.

Para muitos educadores, e principalmente os empregadores da mão de obra, a questão do sujeito não se constitui como problema em termos educacionais, pois a formação do trabalhador é algo direcionado unicamente para o mundo do trabalho e, portanto, algo alheio a questões emancipatórias. Deste modo, pouco se compreende das relações entre o processo de escolarização e o trabalho para constituição de um modo de ser sujeito que tenha rupturas com os processos já estabelecidos de tornar tudo em coisa, pois o tudo se resume no objetivo principal da razão instrumental que atende a sociedade de mercado.

Neste termo, o processo de escolarização pode ser compreendido hegemonicamente, com base na tradição cartesiana, como sendo uma separação entre as coisas do corpo e as coisas da alma, que também se apresenta no dualismo da separação entre teoria e prática. 
A preparação escolar nessa concepção de ensino aplicada ao trabalho seria tornar o sujeito trabalhador aquele que possui um saber fazer em completa separação do saber pensar e, para tanto, torna-se específica a unidade escolar como um lugar da aplicação da razão instrumental que resulta em conjuntos de técnicas aplicadas e supostamente neutras.

Nesta concepção de ensino, a formação escolar seria um agregado de conhecimentos para que se possa estabelecer o valor da força de trabalho. Todo o empenho na formação escolar seria o de agregar mais valor de força de trabalho para ser vendida no mercado de trabalho com um valor que o inclua como sendo o "sujeito capacitado".

Nesta vertente, a escola apenas se apresenta como a realização do trabalho informativo e acumulativo para preparar o sujeito para o mercado de trabalho e, neste contexto, o aparelho escolar e, principalmente, os educadores que ali se encontram perdem a função e também são destituídos da condição de intelectuais. Assim, são representados como sendo desqualificados para pensar a produção de sujeitos no campo da cultura.

Um fator decisivo para a desqualificação do educador no âmbito do aparelho escolar é o baixo valor que é pago pela realização da força de trabalho. Em virtude desse fato, por muitas vezes, alertei os alunos do curso de licenciatura de que o Estado pode pagar o valor baixo pela hora aula, mas o educador deve trabalhar com qualidade, valorizando o seu próprio trabalho. Em outras palavras, o Estado pode pagar um real pela aula do professor, mas a aula do professor não pode valer um real.

A dinâmica do mercado de trabalho e o aspecto especulativo da sociedade de mercado impõem outras diversas situações ao sujeito, que o comprometem em termos educativos e, por consequência, a sua própria saúde. A primeira delas é a possibilidade do desemprego, tendo como resultado principal uma condição de desamparo do trabalhador. A segunda causa seria que, uma vez empregado, o sujeito encontra-se numa situação de desqualificação, pois a rotina sem sentido no trabalho e o baixo valor pago pela força de trabalho determinam os aspectos subjetivos na maneira como este se representa no mundo do trabalho.

Esse pressuposto educacional na interface com o trabalho está pautada numa teoria educativa centrada na memória do sujeito e de uma escola que se apresenta destituída completamente do mundo do trabalho. No entanto, quando a escola se propõe preparar o sujeito para o trabalho, o faz de maneira equivocada, tornando a própria unidade escolar uma unidade de fábrica. 
Neste caso, há dois polos que se afastam da verdade em relacionar-se com o processo de escolarização e o mundo do trabalho. De um lado, há um modelo de escola que nega o trabalho manual e faz dos conteúdos uma abstração sem sentido para os elementos da vida. De outro lado, há um modelo que faz da escola o chão de fábrica, em que os conteúdos escolares são práticas e são representados como sendo a leitura e a aplicação pragmática, como a leitura e a aplicação dos catálogos de máquinas. ${ }^{1}$ Neste caso, o aluno é condicionado como operário a estudar o real como sendo a reprodução de coisas.

A verdade da escola não se encontra nem de um lado ou de outro lado e sim numa escola que possa compreender a ciência e seus conteúdos como uma necessidade de enfrentamento do sujeito perante os desafios cruciais para a manutenção da vida. Neste caso, os conteúdos escolares são construções teóricas de modelos de ciência que buscam, através de um processo de abstração, dar conta da realidade e, portanto, elas se encontram numa filiação direta com as reais necessidades das classes econômicas que se encontram no poder político da sociedade.

O trabalho na escola seria um elemento de reflexão de que a sua técnica de execução é estudada como princípio científico de várias abordagens e, principalmente, de que compreendê-lo como uma produção técnica propriamente humana seria compreender, na radicalidade, a filiação de concepção de mundo e de sujeito, e isso também seria a compreensão de que a ciência não é neutra.

A relação entre a escola e a formação do sujeito para o trabalho não se trata somente de um problema de inclusão em virtude de acessibilidade ou em decorrência do tempo livre para estar presente na unidade escolar, e sim de uma inclusão que se faça verdadeiramente e, portanto, que transforme o sujeito em algo que a modernidade espera, ou seja, cidadão. No entanto, o que seria de fato o cidadão?

São muitas as palavras proferidas nas unidades escolares sobre o que é "formar o cidadão" e são diversas as práticas educativas que se direcionam para essa finalidade da constituição da cidadania, mas já não seria o momento de, em poucas palavras, a modernidade reconhecer que encontra dificuldade em instaurar a condição de cidadania como sendo aquela em que o sujeito possui o exercício do direito e o conjunto de deveres perante as coisas da cidade? Isso implicaria também no reconhecimento da impossibilidade de se fazer presente nas decisões que afetam

\footnotetext{
1 Fui aluno de escola técnica e, por destino de vida, também tornei-me professor de escola técnica. Ocupando esta dupla posição (aluno e professor), foi possível reparar que, neste tipo de escola, há pouca compreensão do que seja o mundo do trabalho.
} 
diretamente a organização da cidade e, principalmente, na produção dos modelos das condições de sua própria subsistência.

Neste caso, fica muito simples constatar que "jamais fomos modernos" (LATOUR, 2000), pois há poucas situações de escolhas em relação aos modelos que são adotados para garantir a organização ou o modo de subsistência no interior das cidades. As dificuldades encontram-se na maneira de sermos sujeitos coletivos e isso implica que:

\begin{abstract}
A modernidade possui tantos sentidos quantos forem os pensadores ou jornalistas. Ainda assim, todas as definições apontam, de uma forma ou de outra, para a passagem do tempo. Através do adjetivo moderno, assinalamos um novo regime, uma aceleração, uma ruptura, uma revolução do tempo. Quando as palavras "modernos", "modernização" e "modernidade" aparecem, definimos, por contraste, um passado arcaico e estável. (LATOUR, 2000, p. 15).
\end{abstract}

Assim, de um lado, vive-se numa coletividade na modernidade em que pouco se compreende o conjunto do seu funcionamento e em que a educação fica reduzida ao aplicativo ferramental de somente inserir o sujeito no social.

Tendo a realização do trabalho como possibilidade de encontrar a própria subsistência, na modernidade, produz-se um tipo de sujeito que se encontra na dificuldade de realizar-se plenamente, pois este se encontra na posição de instrumento, e surge o desconforto em decorrência de o sujeito ser interpretado como objeto.

Por outro lado, o lema democrático na modernidade é a inclusão, mas pouco se quer saber onde está sendo incluído o sujeito neste ambiente social, em que os processos de bárbarie são adquiridos como aspectos da normalidade de um social que, em virtude de suas contradições, promove o adoecimento e ampliação de aspectos da violência.

A matematização dos indicadores sociais da violência, como, por exemplo, a morte por homicídio, faz com que sua aceitabilidade seja permitida, pois eliminam-se as histórias de vida dos sujeitos e apresentam-se apenas os dados; portanto, a tentativa permanente de fazer com que as engrenagens entre a educação e o trabalho funcionem sem os ruídos que se apresentam no campo das relações humanas é tida como sendo o normal.

Neste caso, uma concepção pautada numa proposição crítica não seria a de eliminar os ruídos da modernidade e sim a de interpretá-los como uma mensagem de 
que algo não vai bem na modernidade e a de poder dar outros sentidos para o modo como são construídas as práticas sociais.

\section{EDUCAÇÃO E DESENVOLVIMENTO: O PROCESSO DE ESCOLARIZAÇÃo COMO ELEMENTO NECESSÁRIO PARA A EMANCIAPAÇÃO DO SUJEITO}

O senso comum associar o desenvolvimento social e o crescimento econômico com o grau de escolarização dos sujeitos tem sido recorrente. Parte-se do pressuposto de que não há uma relação direta entre esses fatores, ou seja, uma sociedade pode alcançar grau elevado de escolarização do sujeito, mas este pode estar vivendo numa sociedade com baixo nível de desenvolvimento e crescimento econômico.

Contudo, será difícil encontrar alguma sociedade que alcance alto grau de desenvolvimento e crescimento econômico com os sujeitos possuindo baixo grau de instrução escolar. Partimos do argumento de que a educação escolar pode se constituir como elemento necessário e diferencial para a emancipação do sujeito.

Em contraposição a essa situação e tendo como base que a educação escolar é algo funcional para a manutenção da sociedade de mercado, como seria possível pensar numa ruptura da subordinação do sujeito em relação à máquina para a realização de sua própria emancipação?

A crítica que se deveria estabelecer no campo educacional para a instauração do sujeito emancipado seria a de reconhecer que não se controlam, em grande parte, os diversos determinantes que realizam sua perda da liberdade e sua subordinação aos determinantes da sociedade de mercado. Neste caso, para se responder a essa questão educacional, há que se conceituar a emancipação do sujeito perante a sociedade de mercado.

Compreende-se a emancipação do sujeito como sendo uma condição de sua autonomia em pensar e fazer coisas e, simultaneamente, em pensar que todos são dependentes em pensar e fazer as mesmas coisas. $\mathrm{O}$ corte entre o sujeito alienado e o crítico seria o grau de reconhecimento dessa contradição no modo de existir e, principalmente, a possibilidade de responsabilizar-se pelos seus próprios modos de ser. Neste caso, a educação escolar seria um instrumento de fato e a peça fundamental, pois ela pode inserir no sujeito um modo de existir como sendo o sujeito crítico. No entanto, o que seria o sujeito crítico? 
Em poucas palavras, o sujeito crítico é aquele que se encontra em crise e, portanto, aquele que reconhece os diversos paradoxos de sua própria existência em sociedade. Penso que o primeiro reconhecimento paradoxal do sujeito crítico é o de que sua própria existência implica num processo de destruição dos recursos naturais e, portanto, o comprometimento de sua existência interfere na existência de outras espécies.

Neste aspecto, o sujeito crítico deveria reconhecer as dificuldades tênues na manutenção da vida humana na Terra e incorporar o conjunto dessas preocupações para todas as outras espécies de vida do planeta. Isso, em parte, já produz alterações por completo no campo das relações educativas e, portanto, a implicância radical naquilo que se denomina como sendo sustentabilidade.

Todos aqueles que trabalham direta ou indiretamente no campo educacional e tecnológico deveriam ter, por si mesmo, uma pergunta básica, qual seja: como seria possível manter a produção e o consumo de aproximadamente sete bilhões de habitantes do planeta levando em consideração a manutenção do ecossistema?

A demanda da existência e a ampliação populacional implicam em problema para ser enfrentado por diversas esferas do conhecimento, e no campo educacional isso seria numa modalidade de ensino que abandone uma razão instrumental regida pela lógica do capital para um tipo de saber que tenha como base a crítica da crítica um saber em constante movimento de seus pressupostos estabelecidos como verdade absoluta.

Esse tipo de saber radical na questão ecológica precisaria de uma escola que fomente um tipo de ensino que permita ao sujeito pensar constantemente em mudanças favoráveis para a manutenção da vida, tendo como base o respeito pela integridade de todas as espécies de seres vivos que habitam esse planeta. É preciso reconhecer que:

O planeta Terra vive um período de intensas transformações técnicocientíficas, em contrapartida das quais engendram-se fenômenos de desequilíbrios ecológicos que, se não forem remediados, no limite, ameaçam a vida em sua superfície. Paralelamente a tais perturbações, os modos de vida humanos individuais e coletivos evoluem no sentido de uma progressiva deterioração. As redes de parentesco tendem a se reduzir ao mínimo, a vida doméstica vem sendo gangrenada pelo consumo da mídia, a vida conjugal e familiar se encontra frequentemente "ossificada" por uma espécie de padronização dos comportamentos, as relações de vizinhança estão geralmente reduzidas a sua mais pobre expressão. (GUATTARI, 2009, p. 7-8). 
Em termos educacionais, o problema é a existência das possibilidades em encontrar uma via de manutenção da subsistência de todas as espécies e, portanto, uma educação para realização de trabalho que não comprometa a diversidade de vidas. Trata-se de romper com o pensamento que se limita a:

[...] geralmente se contentar em abordar o campo dos danos industriais e, ainda assim, unicamente numa perspectiva tecnocrática, ao passo que só uma articulação ético-política - a que chamo ecosofia - entre os três registros ecológicos (o do meio ambiente, o das relações sociais e o da subjetividade humana) é que poderia esclarecer convenientemente tais questões. (GUATTARI, 2009, p. 8).

No entanto, como seria possível abordar a questão ecológica em esferas tão amplas para além do meio ambiente circunscrito pela sociedade do mercado e abordar as relações sociais e a subjetividade?

Tudo está relacionado na constituição da emancipação do sujeito e o seu adoecimento é apenas uma expressão do sistema capitalista de produção que o torna descompensado. $\mathrm{O}$ indicador dessa forma descompensada de existir se apresenta no modelo capitalista de produção, em que o lucro deve ser imediato, e isso é um elemento que destitui por completo o valor da vida.

Portanto, as diversas formas de manifestação da violência entre os sujeitos nada mais são do que a manifestação de todo um sistema que destitui por completo o valor da vida. Uma educação emancipatória deveria ter como ponto central o valor da preservação da vida de todas as espécies do planeta, e isso poderia ser compreendido na concepção de educar com o sentido mais amplo possível de cuidar da cultura e, portanto, uma educação que implique os sujeitos para formas de cuidados de uns para com outros.

\section{EDUCAÇÃO DO CORPO COMO UMA MODALIDADE DE FORMAÇÃO DO TRABALHADOR}

Ao visitarmos uma linha de produção é comum encontrar pessoas com certo fascínio com a organização do trabalho, pois os gestos corporais são milimetricamente calculados para atender as necessidades técnicas da execução da tarefa. O sujeito que se encontra na linha de produção manifesta no seu corpo um 
conjunto de gestos repetitivos que permitem pensar a educação do corpo como um objeto de estudo em interface com os campos das ciências biológicas e ciências exatas, principalmente, e os processos de aprendizagem como algo que decorre de um longo e complicado circuito neural em que se estabelecem os esquemas de automatização dos movimentos corporais para o controle na aprendizagem motora.

No entanto, parte-se de outro referencial teórico para analisar o controle e a aprendizagem motora, ou seja, a educação do corpo é tratada como um processo mergulhado no social em que a imitação prestigiosa (MAUSS, 1974, p.74) é fundamental para formação do sujeito produtivo. Este deveria também ser compreendido nos campos dos processos identificatórios que se estabelecem entre os sujeitos. Em contrapartida o ponto critico dessa situação seria numa interface entre a educação e a realização do trabalho humano que pudesse permitir ao sujeito realizarse plenamente sua humanidade. São essas possíveis junções que acabam por definir um campo de pesquisa sobre a educação do corpo e suas interfaces com o mundo do trabalho.

Neste caso, todo o processo de controle e aprendizagem motora é algo que demanda um grande esforço do sujeito em produzir a si mesmo. A imitação prestigiosa é o sujeito imitar aquilo que possui uma representatividade social e, portanto, o gesto imitado já possui em si uma força simbólica que se impõe ao sujeito (MAUSS, 1974, p.75).

Os processos identificatórios são aqueles em que somos atraídos por aquilo que fazemos diretamente com nossos vínculos afetivos e, portanto, somos, em grande parte, constituídos pelo desejo de sermos desejados e, para tanto, nos identificamos com a maneira de ser e que possa atrair o outro no desejo em ser desejado. No caso específico do trabalho humano, é a parte em que se pode desenvolver grande parte das habilidades intelectuais, principalmente, as práticas manuais.

As questões de instrumentalizar uma determinada educação de corpo no campo do trabalho o fazem instrumento, mais propriamente, um elemento anexo à máquina. O sujeito nessa condição de encontrar-se subordinado à máquina fica consumido e perde em muito os elementos da qualidade de vida, pois se sente aprisionado em algo que o impede de realizar-se plenamente em torno das capacidades humanas.

Essa condição de o sujeito ser compreendido como anexo à máquina estabelece um problema no tocante à "saúde do trabalhador", principalmente por se encontrar num sistema em que tudo é tratado como mercadoria. 
O agravante para o sujeito na sociedade de mercado é que esta impõe outras circunstâncias diversas, como por exemplo, a competição entre os pares para se manter no cargo da empresa, que aceleram os processos de adoecimento e, principalmente, a saúde que é também, em grande parte, tratada como mercadoria.

Nas relações entre educação e trabalho, é notório que se adoece constantemente na duração da existência humana e, portanto, há difículdade em definir um modelo de vida que possa atender as espectativas do sujeito produtivo na sociedade, ou seja: como podemos definir o sujeito saudável, tendo como referência que somos um processo permanente de adoecimento, ao inseri-lo, por uma educação que o limita e é limitada, no trabalho como aquele que se encontra subordinado à máquina? Para se compreender essa subordinação do sujeito à máquina, é preciso analisar especificamente como esta

[...] realiza-se até o fim o processo da subsunção real do trabalho ao capital, precisamente no sentido (como vimos) de que tal subsunção se manifesta no terreno material do processo de trabalho, então é claro que o próprio corpo do instrumento, sua própria estrutura material, tem a marca dessa subordinação do trabalho. (NAPOLEONI, 1981, p. 95).

Essa subordinação do sujeito à máquina é um fator agravante na questão da saúde do sujeito, pois esse modelo presente no modo de produção capitalista estabelece as condições de impedimento para a satisfação pulsional do sujeito. Uma verdadeira alteração que tenha como pressuposto a emancipação do sujeito seria outra organização do trabalho, portanto,

[...] uma máquina não utilizada de modo capitalista deveria ser uma máquina diversa da que é utilizada de modo capitalista. Em outras palavras: as máquinas, tais como as conhecemos, são frutos de uma tecnologia (e talvez também de uma ciência) que foi toda pensada sobre a base do pressuposto do trabalho alienado. Numa situação diversa, a mudança deveria envolver o próprio processo de conhecimento e de realização tecnológica, do qual a máquina é o resultado. (NAPOLEONI, 1981, p. 95).

O impedimento dessas alterações está também relacionado com a impossibilidade de se pensar e fazer coisas diferentes. Assim, a satisfação do sujeito na sociedade de mercado é voltada exclusivamente para produção e consumo de mercadorias. Pode-se analisar que o ponto de ruptura na questão do sujeito emancipado ou subordinado seria a possibilidade em amenizar os diversos agravantes estabelecidos no interior da sociedade de mercado e estabelecer a dúvida de que é possível fazer coisas de modo diferente. 
Em parte, pode-se afirmar que essa adequação do sujeito à sociedade de mercado é possível, pois ocorre certo encantamento e busca da felicidade nas diversas possibilidades de consumo. No entanto, nem todos podem consumir e o próprio consumo é algo impeditivo para o sujeito tornar-se emancipado, ou seja, ele apenas se distrai em condições aleatórias que não levam em conta o que é ser sujeito numa condição ética e, portanto, não se trata de acumular objetos para a condição de ter e sim para a condição de ser. A escola teria sim um grande papel em redesenhar essa subjetividade do sujeito em aspectos críticos de sua existência, e isso se encontra como uma esperança que venha a se realizar para todos aqueles que ingressam nela.

\section{CONCLUSÃO - EDUCAÇÃO E TRABALHO E O IMPOSSÍVEL NA BUSCA DA EMANCIPAÇÃO DO SUJEITO NO PROCESSO FORMATIVO}

A cada dia que vou para unidade escolar, sinto que, em cada gesto e pensamento que faço como professor transparecem as dificuldades em realizar a crítica do sujeito no conjunto das práticas sociais e, principalmente, das práticas educativas. Observo que a relação entre o aluno e o professor encontra-se congelada num modelo de objeto/coisa em que pouco se consegue movimentar e, muito menos, romper para aspectos da verdade em ser sujeito do saber ser produtivo e consumidor em oposição ao não saber ser o sujeito crítico.

Para a emancipação do sujeito, o problema central seria o de romper duplamente com o modo de produção capitalista, que subordina o sujeito e a máquina e desapropria os bens produzidos coletivamente. Portanto, a primeira passagem seria a de estabelecer uma inversão da relação do sujeito com a máquina, como já indicado anteriormente por Napoleoni (1981).

Essa alteração na relação do sujeito com a máquina para uma situação em que o homem passa a dominar o processo de produção cria as possibilidades da segunda passagem, em que se pode estabelecer uma distribuição mais justa da riqueza produzida coletivamente no mundo trabalho.

Muitas vezes, a relação entre o aluno e o professor pretende se acomodar em apenas querer saber aquilo que é instituído e indicado como saber absoluto. Nada se quer saber sobre o não saber, pois ele afeta diretamente em ter que lidar com a falta. Não seria por acaso que o Capitalismo se resume num modelo pautado no consumo, 
pois, em última instância, o sujeito busca a todo custo preencher o vazio de sua existência.

São poucos os sujeitos que se opõem ao mercado no sentido de estabelecer uma ruptura ao modelo de produção capitalista. Há uma educação escolar que subordina o sujeito desde o início e, portanto, são poucos os alunos que buscaram romper com esse paradigma do saber pleno que se encontra no "mestre explicador" (RANCIÈRE, 2002).

Grande parte dos alunos que conheci se relacionam com o professor como instrumento de uso, criando uma relação de satisfação e atendimento para a demanda imediata. Em parte, isso é uma verdade para aqueles que apresentam desde a educação infantil, uma demanda de necessidades emocionais primárias e transferem para a escola toda a necessidade de solução de questões não resolvidas no campo das relações de amor e ódio que se estabelecem entre os sujeitos.

No entanto, a escola seria uma segunda chance para que o sujeito pudesse se restabelecer no campo das pulsões e dar o melhor destino às pulsões que, basicamente, seria o de poder fazer cultura nos possíveis processos de desvios - a sublimação.

O professor deveria se posicionar na responsabilidade e autoridade em cumprir o dever de apresentar ao aluno o campo da cultura. Por uma relação da demanda do amor, o aluno atende às exigências do professor e cumpre as tarefas que são alheias, principalmente, a sua vontade. Escutei um dia de um colega que tinha pedido demissão da escola em que trabalhava por ter concluído que "[...] nenhum pai de aluno iria querer que seu filho tivesse aula com um professor de educação física com mais idade" e que se "sentia velho para desempenhar a função de educador". Ouvir este tipo de argumento de um educador é lamentável, mas a manutenção desse sistema de exploração no modelo capitalista impõe em todas as esferas o que é a qualidade no campo das relações humanas e, inclusive, determina no campo educacional uma estética do sujeito. Isso não é por acaso, pois todo um mercado de consumo é alimentado pelos gostos instituídos e, no caso dos gostos, no campo escolar, a cultura erudita passa a ser mais um elemento de consumo. Como seria possível romper com a lógica do Capitalismo, mais precisamente,

\footnotetext{
Como evitar que as crianças se prendam às semióticas dominantes ao ponto de perder muito cedo toda e qualquer verdadeira liberdade de expressão? Sua modelagem pelo mundo adulto parece efetuar-se, de fato, em fases cada vez mais precoces de seu desenvolvimento especialmente por meio da televisão e dos jogos educativos. (GUATTARI, 1981, p. 8).
} 
Não se pode evitar esse conjunto de situações que são produzidas nas tramas das relações humanas que se constituem num caldo cultural de símbolos e valores que envolvem as pessoas e instituem o sujeito como aquele que deva possuir o sentimento próprio para o consumo e a dinâmica produtiva. $\mathrm{O}$ que cabe em termos educativos é que se possa fazer fissuras nessa trama do Capitalismo para que o sujeito possa entrar em crise e, portanto, pensar em algo diferente no conjunto das relações pautadas em outros modelos de produção que tenham o sujeito como o centro do processo. Portanto, a crise na educação e no trabalho já não seria o indício de uma possível resposta sobre a questão do sujeito na sociedade de mercado?

Pode-se responder que a crise na educação e no trabalho seriam fissuras no modelo de vida instituído no Capitalismo e a possibilidade de redirecionar para práticas educativas emancipatórias.

Cabe ao educador na posição de intelectual encontrar as respostas provisórias para movimentar sua prática educativa como elemento necessário para produzir o sujeito crítico para o mundo do trabalho e que seja aquele em permanente construção de relações humanas emancipatórias e, portanto, que possa efetivar verdadeiramente o conceito de sustentabilidade. Isso por si só já seria o papel da educação que tenha como objetivo "formar o cidadão". Resta saber se, de fato: seremos educadores capazes de realizar a promessa de preparar aqueles que, a todo o momento, analisem o campo do trabalho como a possibilidade de fazer novas tentativas de sua própria emancipação e também da realização de sua humanidade?

\section{REFERÊNCIAS}

ADORNO, Theodor W. Educação e Emancipação. Tradução de Wolfgang Leo Maar. Rio de Janeiro: Paz e Terra, 1995.

BOURDIEU, Pierre; PASSERON, Jean Claude. A reprodução: elementos para uma teoria do sistema de ensino. Tradução de Reynaldo Bairão. Rio de Janeiro: Francisco Alves, 1982.

BRASIL. Ministério da Educação Pronatec. Brasília: MEC, 2013. Disponível em: $<$ http://pronatec.mec.gov.br/institucional/o-que-e-o-pronatec $>$. Acesso em: 25 ago. 2013.

FOUCAULT, Michel. Vigiar e punir: o nascimento da prisão. Tradução de Ligia M. Ponde Vassallo. Petrópolis: Vozes, 1991.

FREUD, Sigmund. O Mal-Estar na Civilização In: FREUD, Sigmund. Obras 
Completas. Trad. Jayme Salomão. Rio de Janeiro: Imago, 1929,1930-1996. 21v.

FUNDO DE POPULAÇÃO DAS NAÇÕES UNIDAS. Situação da População mundial. Fundo de População das Nações Unidas.2013.

$<$ http://www.unfpa.org.br/populationcounter.htm>. Acesso em: 19 ago. 2013.

GUATTARI, Félix. Caosmose: um novo paradigma estético. Tradução de Ana Lúcia de Oliveira; Lúcia Cláudia Leão. São Paulo: Ed. 34, 2000.

GUATTARI, Félix. Revolução molecular: pulsações políticas do desejo. Tradução de Suely Belinha Rolnik. São Paulo: Brasiliense, 1981.

GUATTARI, Felix. As três ecologias. Tradução de Maria Cristina F. Bittencourt. Campinas: Papirus, 2009.

INSTITUTO BRASILEIRO DE GEOGRAFIA E ESTÁTISTICA. Indicadores Sociais: Uma Análise das Condições de Vida da População Brasileira. IBGE, 2016 Disponível em: < http://biblioteca.ibge.gov.br/visualizacao/livros/liv98965.pdf

>. Acesso em: 30 set. 2013.

INSTITUTO NACIONAL DE ESTUDOS E PESQUISAS EDUCACIONAIS ANÍSIO TEXEIRA. Censo Escolar da Educação Básica: Resumo Técnico. Disponível em: <

http://download.inep.gov.br/educacao_basica/censo_escolar/resumos_tecnicos/resum o_tecnico_censo_educacao_basica_2012.pdf $>$. Acesso em: 27 ago. 2013.

LATOUR, Bruno. Jamais fomos modernos. Tradução de Carlos Irineu da Costa. Rio de Janeiro: Ed. 34. 2000.

MARX, Karl. Introdução à crítica da economia política. In: MARX, Karl.

Contribuições à crítica da economia política. Tradução de Maria Helena Barreiro Alves. 2. ed. São Paulo: Martins Fontes, 1983.

MAUSS, Marcel. As técnicas corporais. In: MAUSS, Marcel. Sociologia e antropologia. Tradução de Mauro W. B. de Almeida. São Paulo: EPU/EDUSP, 1974. 2 v. p. 220.

NAPOLEONI, Claudio. Lições sobre o capítulo sexto (inédito) de Marx. Tradução de Carlos Nelson Coutinho. São Paulo: Livraria Editora Ciências Humanas, 1981.

RANCIÈRE, Jacques. O mestre ignorante: cinco lições sobre a emancipação intelectual. Tradução de Lílian do Valle. Belo Horizonte: Autêntica, 2002.

SENNETT, Richard. O artífice. Tradução de Clóvis Marques. Rio de Janeiro: Editora Record, 2009. 